BMJ Surgery, Interventions, \& Health Technologies

\section{How much is enough? Finding the minimum annual surgical volume threshold for total knee replacement}

To cite: Randsborg P-H, Chen AC. How much is enough? Finding the minimum annual surgical volume threshold for total knee replacement. BMJ Surg Interv Health Technologies 2021;3:e000092. doi:10.1136/ bmjsit-2021-000092

Received 21 April 2021 Accepted 11 May 2021

\section{Linked}

http://dx.doi.org/10.1136/ bmjsit-2020-000072

http://dx.doi.org/10.1136/ bmjsit-2021-000102

Check for updates

(c) Author(s) (or their employer(s)) 2021. Re-use permitted under CC BY-NC. No commercial re-use. See rights and permissions. Published by BMJ.

${ }^{1}$ Sports Medicine Institute, Hospital for Special Surgery, New York, New York, USA

${ }^{2}$ Dept. of Orthopedic Surgery, Akershus University Hospital, Lørenskog, Akershus, Norway ${ }^{3}$ Department of Health Policy and Research, Weill Cornell Medical College, New York, New York, USA

Correspondence to Dr Per-Henrik Randsborg; Per-Henrik.Randsborg@ahus.no
There is compelling evidence that the outcome of total knee replacement (TKR) depends on the annual caseload of the surgeon and the institution. ${ }^{1-3}$ The fact that high-volume centres have better outcomes is so well known that patients themselves increasingly seek treatment at high-volume institutions. $^{4}$

But how do we determine the surgical volume threshold that constitutes an acceptable risk?

In the recent article by Okoro et al, data from nearly 170000 TKR recipient in Ontario, Canada, were analysed using a state of the art restricted cubic spline (RCS) analysis. ${ }^{5}$ The authors identified an inflection point for increased probability for early revision or infection at 70 annual cases, after which the risk of complications plateaued. However, risk reduction continued even beyond an annual caseload of 70 , highlighting the value of treatment by high-volume surgeons.

This method of identifying the surgical volume threshold differs from previous studies conducted in the last 10 years (table 1). While some papers fail to mention their methods for defining the volume groups, others have largely split the data by quartiles. This results in more or less arbitrary thresholds that are more dependent on local healthcare structure and population size than providing clinical meaningful volume categories. Due to varying methods for defining the volume groups, the lowest volume category in one study ${ }^{6}$ would have been defined as the highest volume category in another. ${ }^{7}$ Clearly, if the goal is to identify the annual caseload that reduces complications and produce meaningful thresholds that surgeons and institutions can aim to achieve, the volume categories should not be defined a priori. This methodological flaw is corrected by the RCS analysis, which uses the dataset to identify the inflection point to identify the actual caseload threshold where the risk of complications is reduced.

However, it is unlikely that the threshold of 70 annual cases to reduce risk of complications is universal. Like any surgery, TKR surgery is composed of teamwork and environmental factors, such as healthcare structure and population demographics, which influence the outcome. Okoro et al suggest that all communities with available real-world data perform similar RCS analysis to identify the caseload threshold relevant to their population. It should therefore be mentioned that Yu et al published a similar RCS analysis from Taiwan in 2019. ${ }^{8}$ They found the inflection point to be somewhat lower in their population, at 50 cases per year, proving the point that the caseload threshold varies between populations. Differences in specialty training practices and best practices across nations affect volume threshold estimates. We predict that future research will produce new and different surgical volume thresholds to reduce complications, and it is unlikely that a definite answer will be possible to find. It is more likely that the true annual caseload threshold varies over time, as surgical training, implant design and population characteristics change.

Another challenge in determining acceptable caseload thresholds is that different complications will have different volume thresholds. Existing literature on the effect of surgical volume has used a spectrum of different outcomes, including 30-day readmission, revision rate, radiological implant alignment, ${ }^{9}$ surgical site infection and length of hospital stay (table 1). Different complications will have different etiologies, not all related to the experience of the surgeon. Hospital environment, population characteristics, postoperative care and rehabilitation facilities all play a part in securing a good outcome after arthroplasty surgery. For example, length of stay is dependent on 


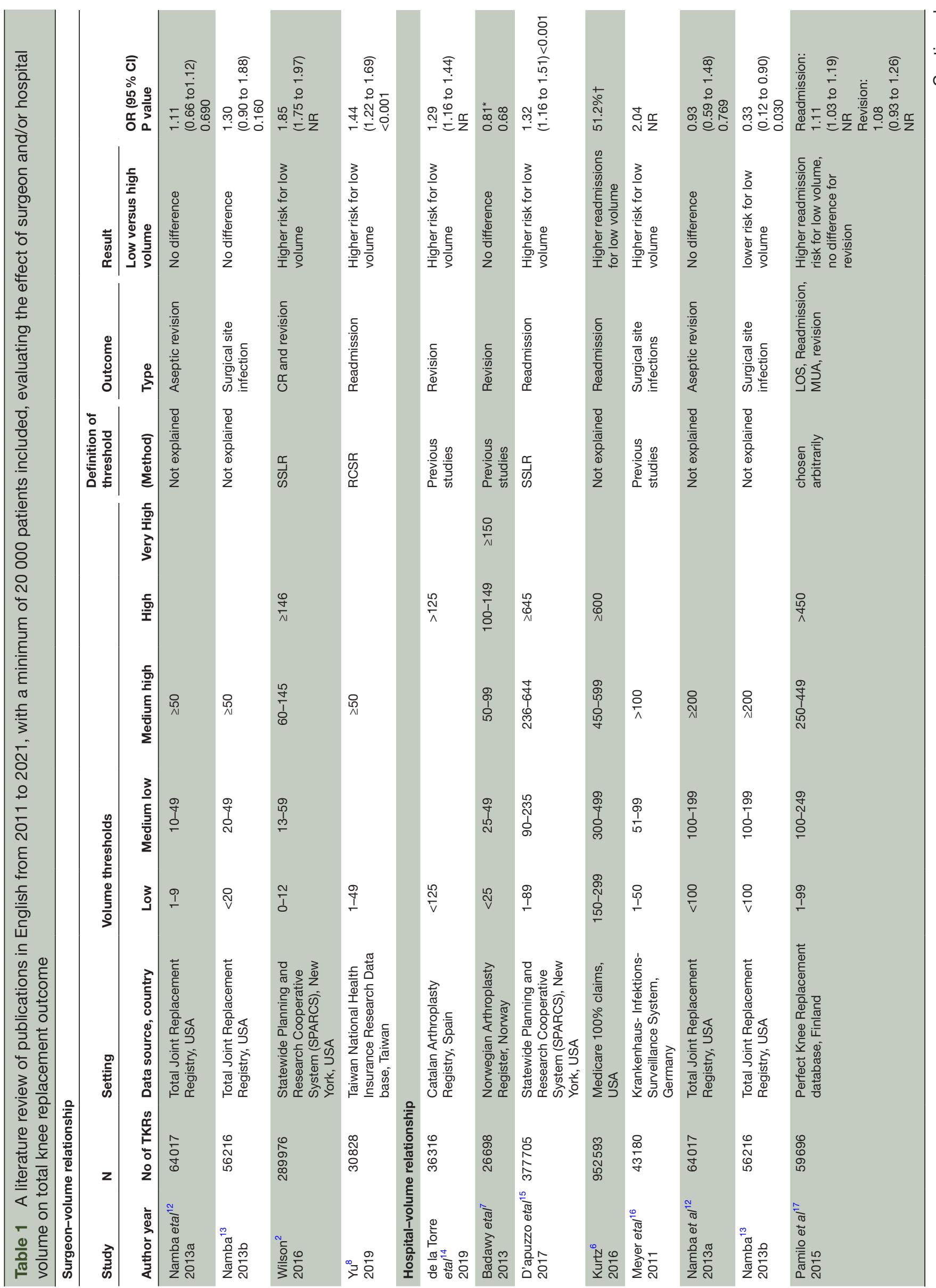

$\underset{\sim}{\longrightarrow}$ 
multiple factors, not least the hospital capacity and the proximity of a potential rehabilitation facility or the home of the patient. A longer hospital stay in a rural hospital with low surgical volume may therefore not be an indication of poor quality. Furthermore, not all of these complications necessarily constitute a clinically meaningful difference for the patient (eg, implant alignment may not have clinical relevance). As such, the revision rate is probably the best outcome measure, representing a hard end-point with a clear consequence for the patient. However, even revision rates are subject to individual variation thresholds by the revision surgeon, and local traditions such as patella resurfacing or not. Defining the minimal surgical volume threshold is clearly not an easy task.

However, the true surgical volume threshold is perhaps not that important. The point is that there is little doubt that surgical volume matters, and the crucial question is what to do with this knowledge. Some authors have suggested that low-volume surgeons should either stop doing the procedure, or do more of it. ${ }^{10}$ There are many arguments for centralisation, as TKR are nearly always an elective procedure that may be postponed. However, travelling for hours to receive care is not always possible, and removing TKR service from local hospitals reduces both the availability and the quality of care. Caring for patients operated by other surgeons is difficult, especially if the patient has had a type of surgery you do not perform yourself, and interrupts the continuity of a patient's care. Furthermore, patients treated at high-volume institutions differ from those of low-volume institutions, ${ }^{11}$ meaning that changing the population flow might affect the caseload thresholds, which are probably constantly changing anyway.

Still, there is no denying the effect of surgical volume on outcome quality. The improved, and likely more accurate, caseload thresholds estimated by Okoro et al and $\mathrm{Yu}$ et al provide valuable information that can guide decisionmakers when organising the arthroplasty service in the community. An effort to reach a minimum of caseload in most centres should be combined with efforts to improve the quality of the care in low-volume institutions, so that uniform healthcare and equity can be reached while preserving access to care.

\section{Twitter Per-Henrik Randsborg @randsborg}

Contributors P-HR wrote the initial draft and screened the literature abstracts. ACC performed the literature search, completed the table and revised the manuscript.

Funding The authors have not declared a specific grant for this research from any funding agency in the public, commercial or not-for-profit sectors.

Competing interests None declared.

Patient consent for publication Not required.

Provenance and peer review Commissioned; internally peer reviewed.

Open access This is an open access article distributed in accordance with the Creative Commons Attribution Non Commercial (CC BY-NC 4.0) license, which permits others to distribute, remix, adapt, build upon this work noncommercially, and license their derivative works on different terms, provided the original work is properly cited, appropriate credit is given, any changes made 
indicated, and the use is non-commercial. See: http://creativecommons.org/ licenses/by-nc/4.0/.

\section{ORCID iD}

Per-Henrik Randsborg http://orcid.org/0000-0002-7674-1572

\section{REFERENCES}

1 Critchley RJ, Baker PN, Deehan DJ. Does surgical volume affect outcome after primary and revision knee arthroplasty? A systematic review of the literature. Knee 2012;19:513-8.

2 Wilson S, Marx RG, Pan T-J, et al. Meaningful thresholds for the volume-outcome relationship in total knee arthroplasty. J Bone Joint Surg Am 2016;98:1683-90.

3 Reames BN, Ghaferi AA, Birkmeyer JD, et al. Hospital volume and operative mortality in the modern era. Ann Surg 2014;260:244-51.

4 Laucis NC, Chowdhury M, Dasgupta A, et al. Trend toward highvolume hospitals and the influence on complications in knee and hip arthroplasty. J Bone Joint Surg Am 2016;98:707-12.

5 Okoro T, Tomescu S, Paterson JM. Analysis of the relationship between surgeon procedure volume and complications after tota knee arthroplasty using a propensity matched cohort study. BMJ Surg Interv Health Technologies 2021.

6 Kurtz SM, Lau EC, Ong KL, et al. Which hospital and clinical factors drive 30- and 90-day readmission after TKA? J Arthroplasty 2016;31:2099-107.

7 Badawy M, Espehaug B, Indrekvam K, et al. Influence of hospital volume on revision rate after total knee arthroplasty with cement. $J$ Bone Joint Surg Am 2013;95:e131.

$8 \mathrm{Yu}$ T-H, Chou Y-Y, Tung Y-C. Should we pay attention to surgeon or hospital volume in total knee arthroplasty? Evidence from a nationwide population-based study. PLoS One 2019;14:e0216667.
9 Kazarian GS, Lawrie CM, Barrack TN, et al. The impact of surgeon volume and training status on implant alignment in total knee arthroplasty. J Bone Joint Surg Am 2019;101:1713-23.

10 Baker P, Jameson S, Critchley R, et al. Center and surgeon volume influence the revision rate following unicondylar knee replacement: an analysis of 23,400 medial cemented unicondylar knee replacements. J Bone Joint Surg Am 2013;95:702-9.

11 Anis HK, Arnold NR, Ramanathan D, et al. Are we treating similar patients? hospital volume and the difference in patient populations for total knee arthroplasty. J Arthroplasty 2020;35:S97-100.

12 Namba RS, Cafri G, Khatod M, et al. Risk factors for total knee arthroplasty aseptic revision. J Arthroplasty 2013;28:122-7.

13 Namba RS, Inacio MCS, Paxton EW. Risk factors associated with deep surgical site infections after primary total knee arthroplasty: an analysis of 56,216 knees. J Bone Joint Surg Am 2013;95:775-82.

14 Arias-de la Torre J, Valderas JM, Evans JP. Catalan arthroplasty register Steering Committee (RACat). Differences in risk of revision and mortality between total and Unicompartmental knee arthroplasty. The influence of hospital volume. J Arthroplasty 2019;34:865-71.

15 D'Apuzzo M, Westrich G, Hidaka C, et al. All-Cause versus Complication-Specific readmission following total knee arthroplasty. J Bone Joint Surg Am 2017;99:1093-103.

16 Meyer E, Weitzel-Kage D, Sohr D, et al. Impact of department volume on surgical site infections following arthroscopy, knee replacement or hip replacement. BMJ Qual Saf 2011;20:1069-74.

17 Pamilo KJ, Peltola M, Paloneva J, et al. Hospital volume affects outcome after total knee arthroplasty. Acta Orthop 2015;86:41-7.

18 Singh JA, Kwoh CK, Boudreau RM, et al. Hospital volume and surgical outcomes after elective hip/knee arthroplasty: a riskadjusted analysis of a large regional database. Arthritis Rheum 2011;63:2531-9. 